\title{
Diverticula of the vermiform appendix: a report of nine cases
}

\author{
K. C. CHONG \\ M.B., B.S., M.R.C.Path. \\ Department of Pathology, Faculty of Medicine, University of Malaya, Kuala Lumpur, Malaysia
}

\begin{abstract}
Summary
The incidence, clinical features and pathology of nine cases of diverticula of the appendix in Malaysians are reported. The findings are discussed and compared with those previously reported. The pathogenesis of the lesion in eight cases is unknown. The rare association of lumenal obstruction by a carcinoid tumour and diverticulum formation in the appendix is seen in one case.
\end{abstract}

\section{Introduction}

A lesion that is well documented in Western countries but relatively unknown in Asian countries is diverticula of the vermiform appendix. A recent review of the world literature (Trollope and Lindenauer, 1974) revealed 1,397 cases. Besides being an interesting pathological condition, these lesions are clinically important: diverticula when associated with acute appendicitis are prone to early rupture (Mulsow, 1932; Ladin, 1951); a ruptured diverticulum may predispose to pseudomyxoma peritonei (Lohr, 1922); and, an association with the D13-15 trisomy syndrome has been reported (Favara, 1968).

Diverticula of the appendix are of two types: (1) congenital diverticula, where all the layers of the normal intestinal wall are present; (2) acquired diverticula, where the muscularis propria is absent and the wall of the diverticulum consists only of mucosa and submucosa. These lesions are single or multiple. Of the two types of diverticula, the acquired lesion is by far the more common. In Trollope and Lindenauer's (1974) review, 1,354 of the cases were acquired diverticula and the remaining forty-three congenital. The pathogenesis of this lesion remains controversial.

This is a report of nine cases of diverticula of the appendix in Malaysians.

\section{Materials and methods}

The surgical pathology records of 2,250 appendix specimens collected in the Department of Pathology, University of Malaya, Kuala Lumpur, Malaysia, from its inception of service in July 1967 untih September 1975 were reviewed and nine cases of diverticula were found. $\mathrm{H}$ and $\mathrm{E} 5 \mu \mathrm{m}$ sections of the abnormal appendix specimens were re-examined All gross and microscopical pathological findings were recorded. Clinical charts of the patients were analysed and all relevant clinical data tabulated. Finally, a clinicopathological study of these nine cases was undertaken.

\section{Results}

The nine cases represented an incidence of $0.4 \%$

Clinical data from the nine patients are shown in Table 1.

Age at presentation of the nine patients ranged from 19 to 69 years, with two-thirds of the patients aged below 40 years. Eight were male and one was

TABLE 1. Clinical data in acquired diverticula of the appendix

\begin{tabular}{ccccccc}
\hline Case & $\begin{array}{c}\text { Age } \\
\text { (years) }\end{array}$ & Sex & \multicolumn{1}{c}{ Race } & Presenting symptoms & $\begin{array}{c}\text { Duration of } \\
\text { symptoms }\end{array}$ & Clinical diagnosis \\
\hline 1 & 30 & F & Chinese & Pain right iliac fossa & 2 days & Acute salpingitis \\
2 & 64 & M & Chinese & Pain right iliac fossa & 3 days & Acute appendicitis \\
3 & 21 & M & Indian & Pain right iliac fossa & 1 day & Acute appendicitis \\
4 & 57 & M & Indian & Asymptomatic & - & Right inguinal hernia \\
5 & 69 & M & Chinese & Pain right iliac fossa & 36 hours & Acute appendicitis \\
6 & 39 & M & Chinese & Pain right iliac fossa & 1 day & Acute appendicitis \\
7 & 28 & M & Indian & Pain right iliac fossa & 7 days & Acute appendicitis \\
8 & 19 & M & Malay & Pain right iliac fossa & 3 days & Acute appendicitis \\
9 & 38 & M & Chinese & Pain right iliac fossa & 1 day & Acute appendicitis \\
\hline
\end{tabular}




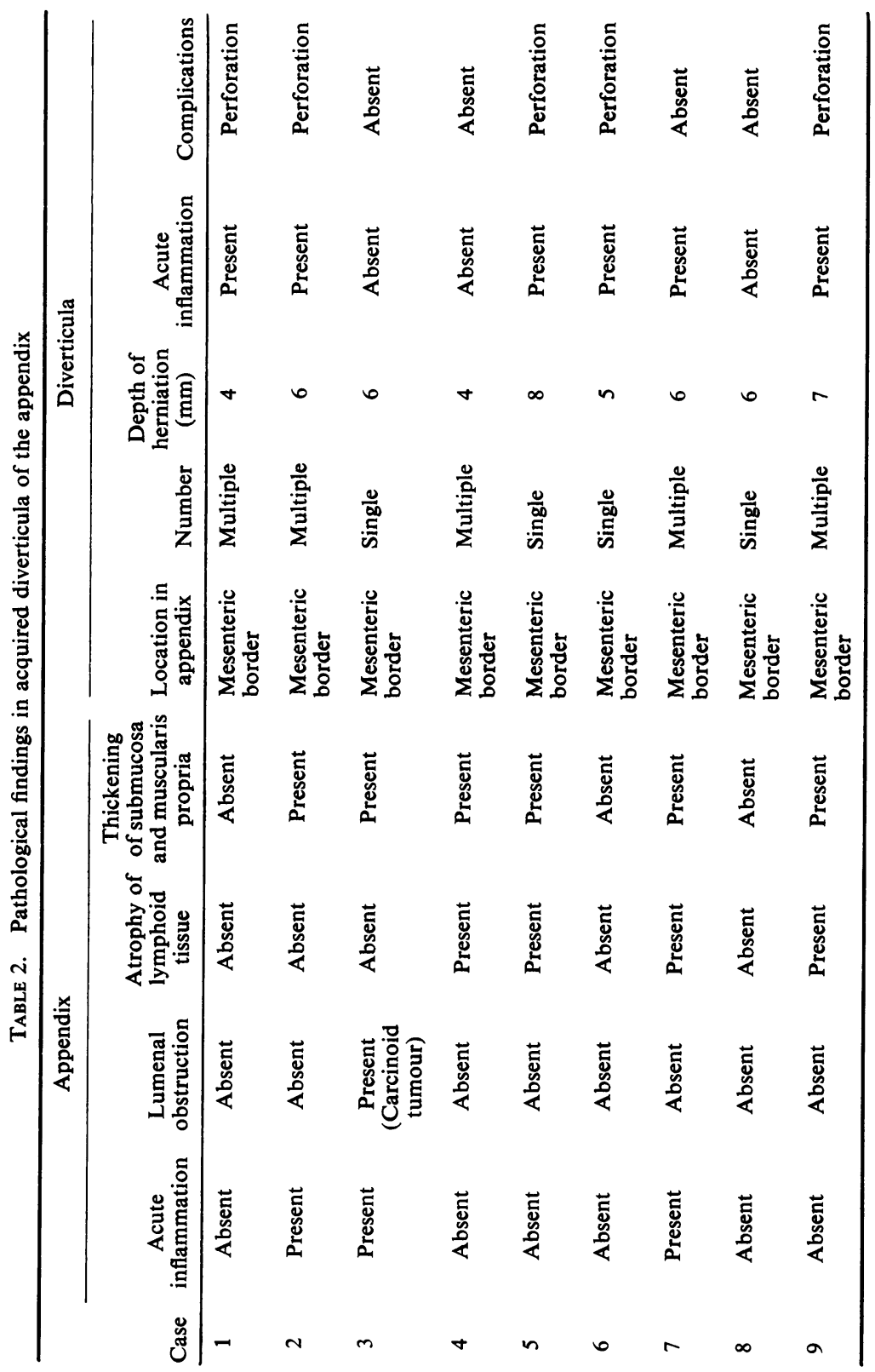




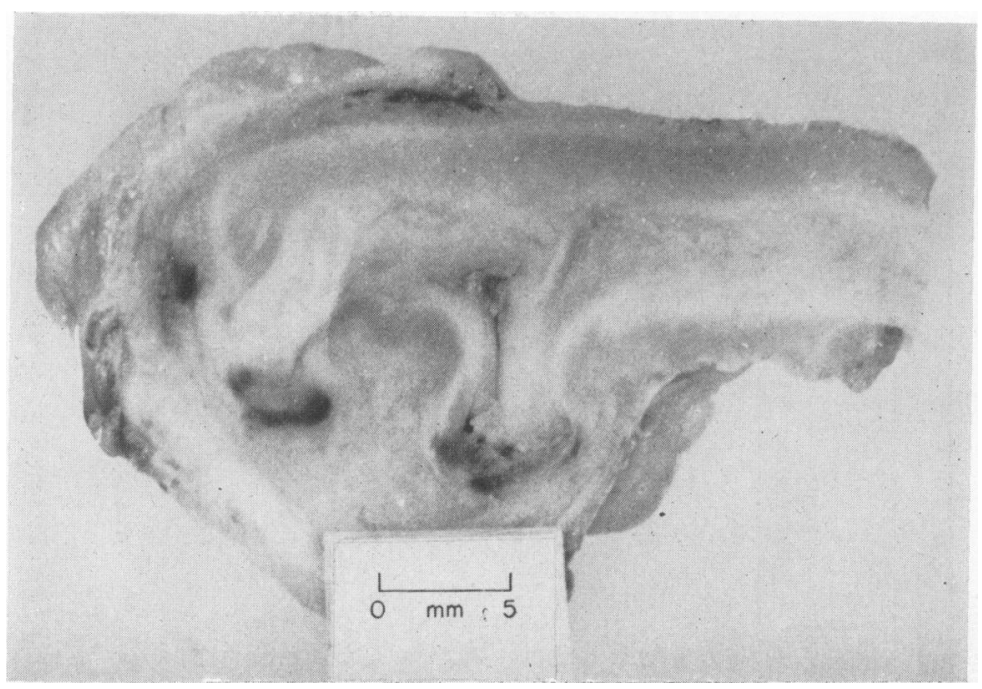

FIG. 1. Two diverticula located along mesenteric border of appendix.

female. Five were Chinese, three Indian, and one Malay.

The presenting symptom in eight of the patients was the onset of pain localized to the right iliac fossa varying in duration from 1 to 7 days, the majority $>$ $36 \mathrm{hr}$. The clinical diagnosis was acute appendicitis in seven and acute salpingitis in one. Emergency appendicectomy was performed in each case. One patient had no symptoms related to the appendix and appendicectomy was incidentally done during herniorrhaphy. None of the cases was recognized to be diverticula of the appendix clinically or at operation.

The post-operative course was uneventful in all cases and there were no deaths.

The pathological findings in the nine appendix specimens are shown in Table 2.

\section{Gross findings}

Five of the appendix specimens from the seven symptomatic patients were inflamed and covered with pus. The remaining symptomatic and the asymptomatic patients had non-inflamed specimens. Diverticula located along the mesenteric border and herniated to a depth of 4-8 $\mathrm{mm}$ into the mesoappendiceal fat were present in all the specimens (Fig. 1). The largest number of lesions in one specimen was five. In each of the inflamed appendix specimens a diverticulum located near the tip had perforated into the mesoappendix.

In case 3 , the lumen at mid-appendix was obstructed by a $2 \mathrm{~mm}$ yellow mural nodule, and a single diverticulum was found distal to the site of obstruction. In all other cases there was no lumenal obstruction.

\section{Microscopical findings}

All the diverticula were of the acquired type. Each lesion was a result of herniation of the mucosa and submucosa of the appendix into the mesoappendiceal fat through a defect of the muscular wall (Figs $2 \& 3$ ) In the perforated specimens, the site of perforation was at the fundus of a diverticulum in each case (Fig. 4). There was acute suppuration in and around the perforated lesions and inflammation had extended through the mesoappendix and over the surface of the appendix specimens. Three of the five specimens showed diffuse acute inflammation.

In case 3, the mural nodule found obstructing the lumen at mid-appendix was a typical carcinoid tumour (Fig. 5) composed of small nests and larger masses of regular, polygonal to cuboidal epithelial cells with deeply chromatic round to oval nuclei and moderate amount of faintly eosinophilic cytoplasm. There was no glandular differentiation. Cellular anaplasia and mitoses were absent. Both silver impregnation technique and diazo stain showed the presence of scanty argentaffin granules in the cytoplasm of some tumour cells. Despite the benign appearance the tumour had infiltrated through all the layers of the appendiceal wall and obstructed the lumen of the appendix (Fig. 6).

Atrophy of mucosal lymphoid tissue was observed in four appendix specimens and in six specimens, including case 3 , there was thickening of the submucosa and muscularis propria.

\section{Discussion}

Diverticula of the intestines are rare (Vine, 1941) and diverticula of the appendix have not been previously reported from Malaysians. Yeoh (1961) in 


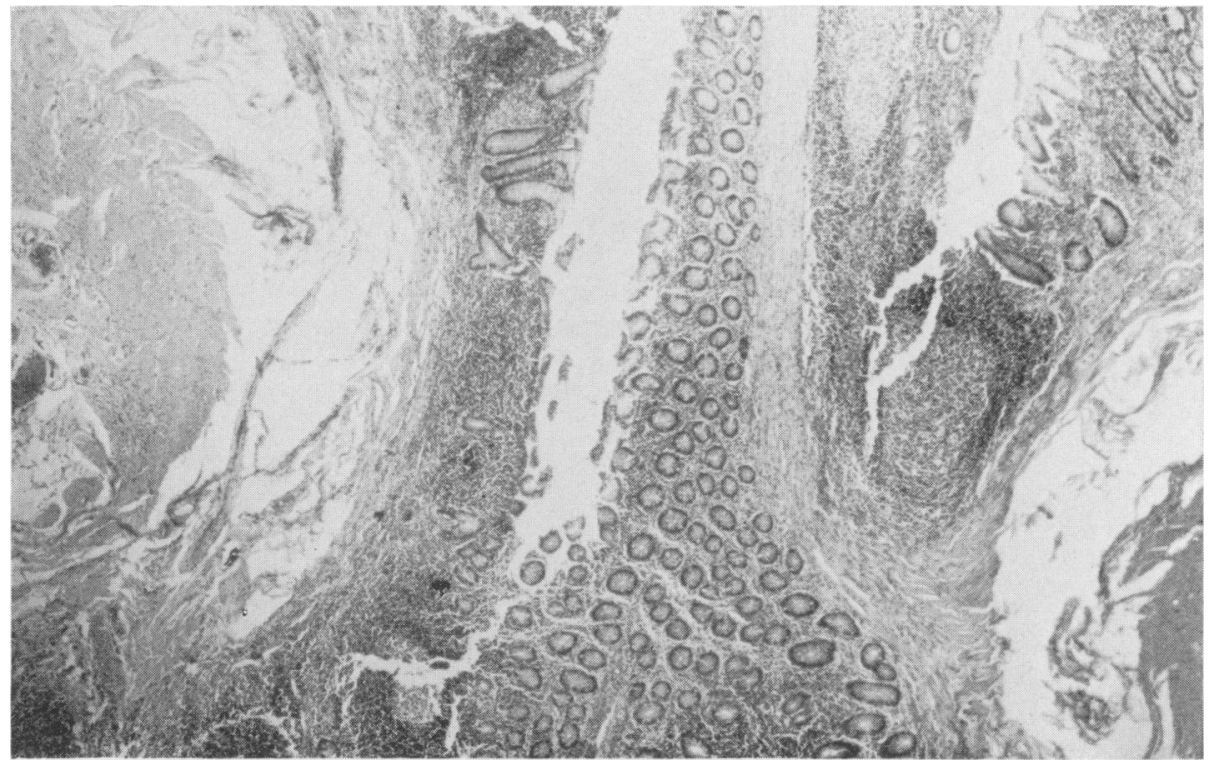

Fig. 2. Diverticulum herniating through defect in muscular wall of appendix. $(H$ and $E, \times 26$.

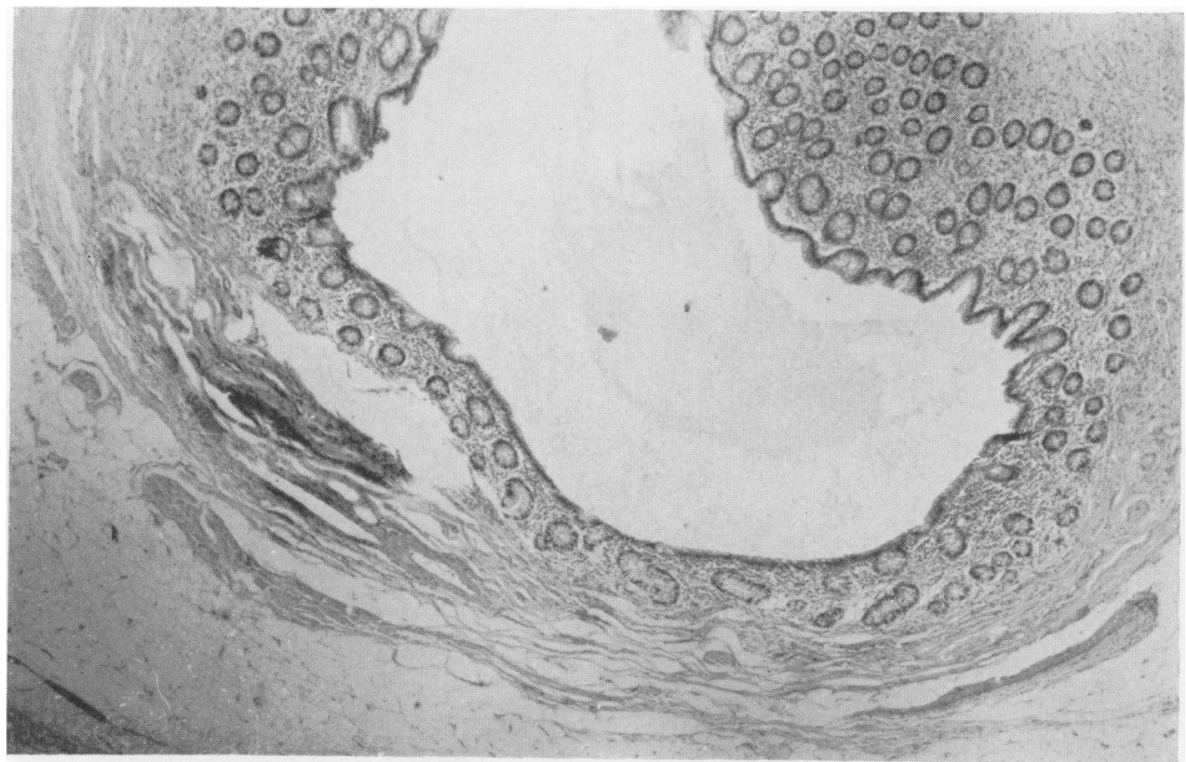

Fig. 3. Fundus of diverticulum, composed only of mucosa and submucosa of appendix, embedded in mesoappendiceal fat. $(\mathrm{H}$ and $\mathrm{E}, \times 26$.

his analysis of 5,067 cases of acute appendicitis in Singapore found no instance of diverticula. However, the rarity of diverticula of the appendix in Malaysians is more apparent than real as is shown by this study where nine cases were found in one department over a period of 8 years. One explanation is that it is difficult to diagnose this lesion clinically and at operation. A high index of suspicion is required for its recognition.

In an attempt to define the symptomatology of acute diverticulitis of the appendix, Deschênes, Couture and Garneau (1971), in a comparative study of patients with acute diverticulitis and acute appendicitis, noted that in those with diverticula, the 


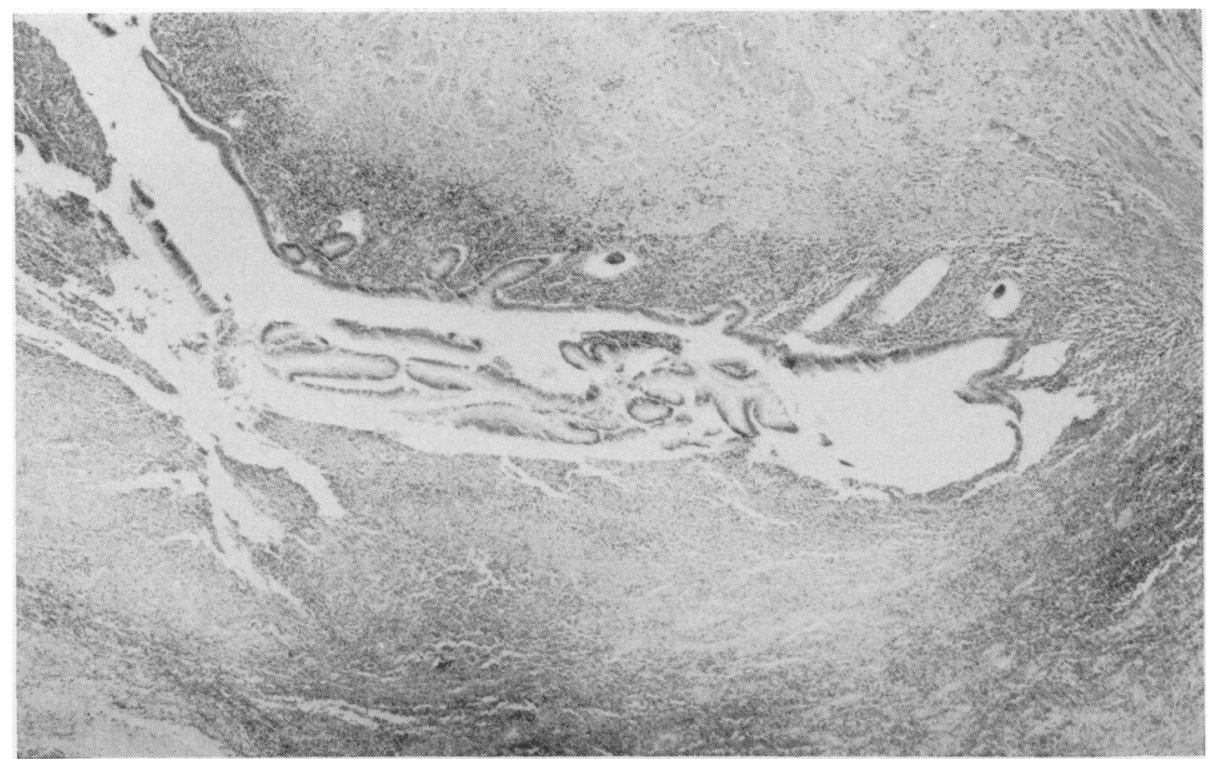

Fig. 4. Diverticulum, perforated at fundus, showing acute suppuration in and around site of perforation. ( $\mathrm{H}$ and $\mathrm{E}, \times 26$.)

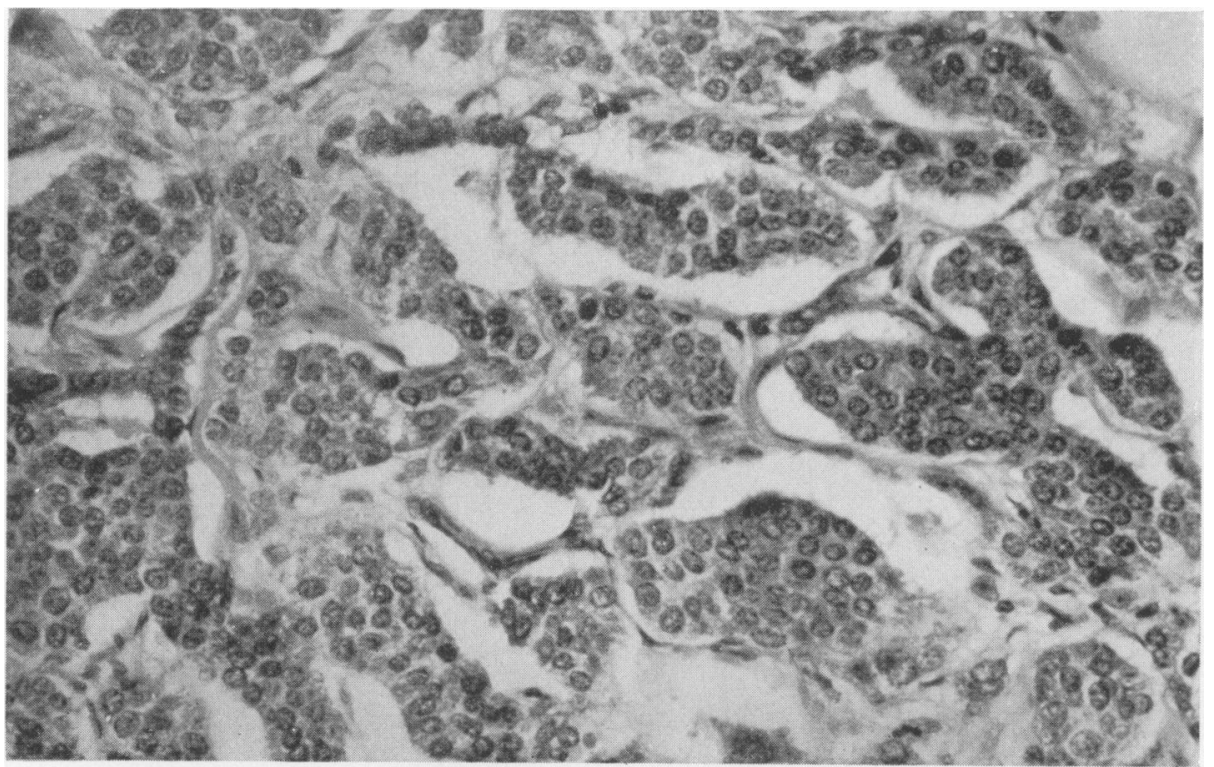

FIG. 5. Carcinoid tumour of appendix composed of nests and larger masses of regular neoplastic epithelial cells. (H and E, $\times 260$.)

abdominal pain was milder and of longer duration, the patients were older and abscess formation and perforation were more advanced at operation.

In this study all the nine cases of diverticula were not recognized clinically or at operation and the diagnosis was only made during pathological examination of the specimens. All the cases were of acquired diverticula. The estimated incidence is $0.4 \%$ which is a minimal incidence as no specific effort was made to identify the lesion during examination of the appendix specimens over the period of this study. In the literature the incidence of acquired diverticula varies from $0.004 \%$ (Feldman, 1957) to $1.9 \%$ (Wolff, 1938). 


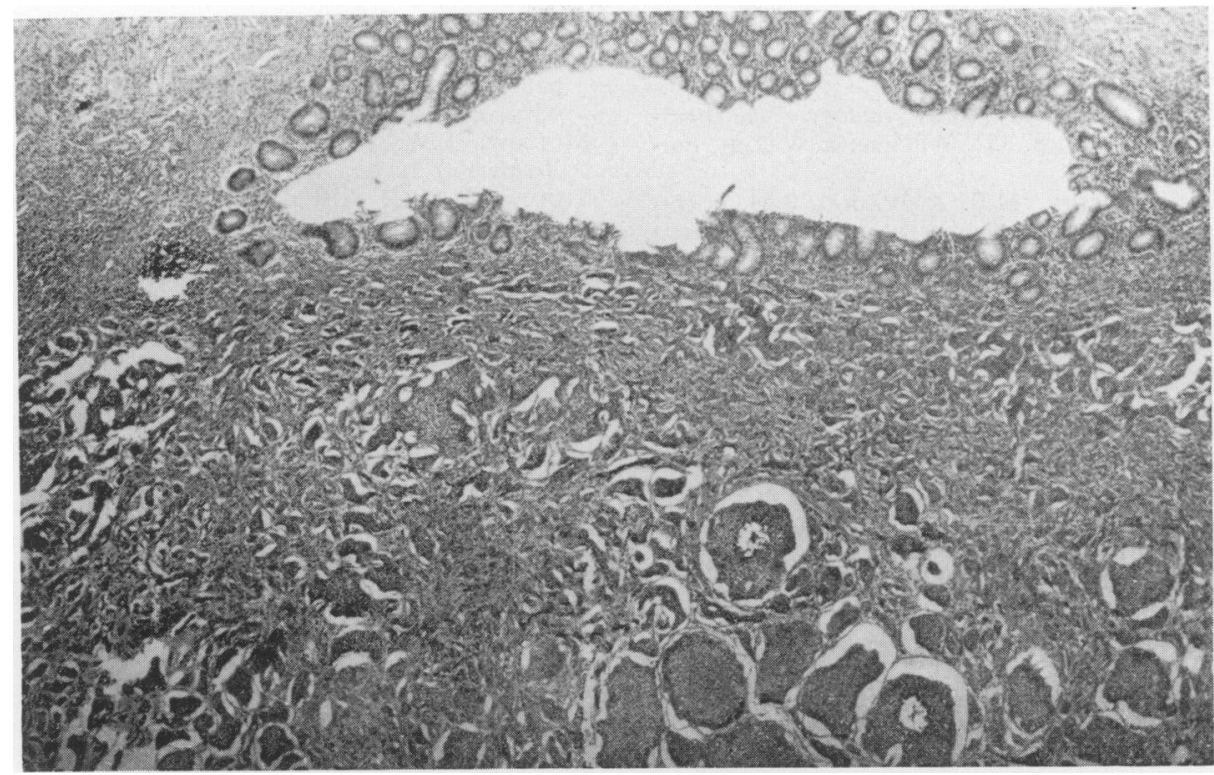

FIG. 6. Carcinoid tumour obstructing lumen of appendix. $(\mathrm{H}$ and $\mathrm{E}, \times 110$.)

The lesion was found in all the three main groups of Malaysians: Malays, Chinese, and Indians. The clinical features of diverticula in this series of patients are in many respects similar to those previously reported (Collins, 1936; Wolff, 1938; Jean, 1964; Trollope and Lindenauer, 1974): there is a male predominance; the lesion occurs in adults of all age groups but mostly in patients aged below 40 years, presenting symptoms are those of acute appendicitis.

In line with the experience of others (Mulsow, 1932; Ladin, 1951), perforation is a frequent complication which was observed in five of the nine cases. There was no instance of pseudomyxoma peritonei.

Jean (1964) and Deschênes et al. (1971), among others, pointed out that other abnormal findings are present in appendix specimens with diverticula. These include a small appendiceal lumen, thickening of the submucosa and muscularis propria and an atrophy of mucosal lymphoid tissue. All these changes were observed in some of the specimens in this series. Of special significance is muscular hypertrophy which is considered an important factor in the pathogenesis of acquired diverticula of the appendix (Stout, 1923; Edwards, 1934; Wilson, 1960).

Many mechanisms have been proposed to explain the pathogenesis of acquired diverticula (Jean, 1963) but this remains controversial. Recent authors (Stout, 1923; Gramse, Dockerty and Waugh, 1949; Trollope and Lindenauer, 1974) consider mechanical or functional lumenal obstruction with intralumenal hypertension, especially when associated with abnormal muscular contraction in the appendix, to be an important pathogenic mechanism responsible for the development of acquired diverticula. In this series, the pathogenesis of the diverticula is unknown in eight of the cases. In one case (Case 3), a carcinoid tumour was found obstructing the lumen at mid-appendix and a single diverticulum had developed distal to the site of obstruction. The findings in this case lend support to the above theory. The association of tumour obstruction and diverticulum formation in the appendix is a rare phenomenon. Trollope and Lindenauer (1974) reported one case and in their review they mentioned two previous instances of such an association (MacCarty and McGrath, 1911; Wilkie, 1921). In all these cases, obstruction was due to carcinoma. The only case where a carcinoid tumour was responsible for obstruction was in case 3 .

The results of this study show that the rarity of diverticula of the intestines and appendix in Malaysians is more apparent than real and more studies are needed to elucidate the true incidence of this condition in Malaysians.

\section{References}

Collins, D.C. (1936) Diverticula of the vermiform appendix: a study based on thirty cases. Annals of Surgery, 104, 1001.

Deschênes, L., Couture, J. \& Garneau, R. (1971) Diverticulitis of the appendix: report of sixty-one cases. American Journal of Surgery, 121, 706.

EDWARDS, H.C. (1934) Diverticula of the vermiform appendix. British Journal of Surgery, 22, 88. 
Favara, B.E. (1968) Multiple congenital diverticula of the vermiform appendix. American Journal of Clinical Pathology, 49, 60 .

Feldman, M. (1957) In: Clinical Roentgenologv of the Digestive Tract, Fourth edn, p. 552. Williams \& Wilkins, Baltimore.

Gramse, A.E., Dockerty, M.B. \& Waugh, J.M. (1949) False diverticula of the appendix: a sequel of previous inflammation and rupture of the appendix. A clinical and pathological study. Surgical Clinics of North America, 29, 1189.

JEAN, C. (1963) Diverticules de l'appendice vermiforme. Etude anatomoclinique de 18 observations de faux diverticules. Annales d'Anatomie Pathologique. Paris, 8, 489.

JEAN, C. (1964) Diverticules de l'appendice vermiforme. Laval Médecine, 35, 673.

LADIN, P. (1951) Diverticulosis and diverticulitis of the vermiform appendix: a brief review and report of sixteen cases. Archives of Surgery, 62, 514.

LöHR, W. (1922) Zur Frage des Wurmfortsatzdivertikels und seiner Folgezustande, insbesondere des Pseudomyxoma peritonei. Deutsche Zeitschrift für Chirurgie, 171, 30.

MacCarty, W.C. \& McGrath, B.F. (1911) Clinical and pathological significance of obliteration, carcinoma, and diverticulum of the appendix: Deductions from an examination of 5,000 specimens, with a comparative study of the pathological and clinical histories in 2,000 cases. Surgery, Gynecology and Obstetrics, 12, 211.

Mulsow, F.W. (1932) Diverticulosis of the appendix. Archives of Surgery, 24, 923.

Stout, A.P. (1923) A study of diverticulum formation in the appendix. Archives of Surgery, 6, 793.

Trollope, M.I. \& LindenaUer, S.M. (1974) Diverticulosis of the appendix: a collective review. Diseases of the Colon and Rectum, 17, 200.

VINE, L.E. (1941) Total jejuno-ileal volvulus with jejunal diverticulosis: a case report. Journal of Malaya Branch, British Medical Association, 5, 58.

WILKIE, D.P. (1921) Carcinoma of the appendix causing diverticula of the appendix and acute appendicular obstruction. British Journal of Surgery, 8, 392.

Wilson, R.R. (1950) Diverticula of appendix and certain factors in their development. British Journal of Surgery, 38, 65.

WolfF, E.A. (1938) Diverticula of the appendix. Medical Times of New York, 66, 232.

YEOH, G.S. (1961) Appendicitis: a study of 5,067 cases in the surgical professorial unit, General Hospital, Singapore. Singapore Medical Journal, 2, 148. 